\title{
Make Him an Offer He Can’t Refuse: Avoiding
}

\section{Conflicts through Side Payments*}

\author{
Erik O. Kimbrough ${ }^{a}$ and Roman M. Sheremeta ${ }^{b}$ \\ ${ }^{a}$ Department of Economics (AE1), School of Business and Economics, Maastricht University, \\ P.O. Box 616, 6200 MD Maastricht, The Netherlands \\ ${ }^{\mathrm{b}}$ Argyros School of Business and Economics, Chapman University, \\ One University Drive, Orange, CA 92866, USA
}

October 28, 2010

\begin{abstract}
The equilibrium of a two-stage conflict game with side-payments predicts that with binding stage-one offers, proposers make and responders accept side-payments, generating settlements that strongly favor proposers. When side-payments are non-binding, proposers offer nothing and conflicts always arise. Laboratory experiments confirm that binding side-payments reduce conflicts. However, $30 \%$ of responders reject binding offers, and offers are more egalitarian than predicted. Surprisingly, non-binding side-payments also improve efficiency, although less than binding. With binding side-payments, 98\% of efficiency gains come from avoided conflicts. However, with non-binding side-payments, only $49 \%$ of gains come from avoided conflicts and $51 \%$ from reduced conflict expenditures.
\end{abstract}

JEL Classifications: C72, C91, D72

Keywords: contest, conflict resolution, side payments, experiments

Corresponding author: Erik O Kimbrough, ekimbrough@ gmail.com

* We thank Subhasish M. Chowdhury, Stergios Skaperdas, Ted Turocy, Taylor Jaworski, Luis Alejandro Palacio, seminar participants at Chapman University, Maastricht University and participants at the International Economic Science Association conference for helpful comments. The authors would also like to thank the Economic Science Institute and the International Foundation for Research in Experimental Economics for generous financial support. Any remaining errors are ours. 


\section{Introduction}

Though we hope it needs no explanation, our title is drawn from a famous scene in The Godfather in which Marlon Brando's character, the head of the Corleone crime family, sends his trusted aide to Los Angeles to convince an intransigent movie producer to give his godson a role in an upcoming film. Don Corleone offers to help the producer deal with the unions in exchange for this favor, but when the producer refuses, the Don suggests they “make him an offer he can't refuse" and beheads his prized horse. Having experienced the gravity of underestimating Don Corleone's insistence, the producer acquiesces and the dealings are concluded without further bloodshed. Perhaps the producer believed that the Don could not commit to limiting his demands to the one request and that he would renege in the future. However, had the producer accepted Don Corleone's offer in the first place, costly conflict could have been avoided altogether.

The pervasive threat of conflict in human history has yielded much effort in identifying and adopting institutions and social conventions that prevent conflict. ${ }^{1}$ Here we step back and look at the most basic means of avoiding conflict - paying off one's enemies. We develop and test with laboratory experiments a simple model of conflict avoidance via side payments. We show that when agents can bargain before a conflict, resource transfers are sufficient to render fighting unnecessary, so long as agents can commit themselves to respect the agreement. However, in experiments we observe deviations from the theory in two major ways: 1) when commitment not to fight is guaranteed by accepting a transfer, side payments are less effective at reducing conflict than predicted, but 2) when the decision to enter the fight is not tied to the decision to accept, the ability to offer side payments nevertheless reduces the costs of conflict.

The potential applications of this knowledge are as broad as conflict is ubiquitous in human social life. The use of side payments to avoid conflict can be observed in diverse situations such as countries offering foreign aid to potential belligerents to stave off violence and parents bribing their children to avoid a tantrum. Empirical evidence suggests that families share or offer gifts of food and other items to non-related individuals to deter theft. For example, Schechter (2007) reports that 42 percent of rural Paraguayan households admit giving gifts to potential thieves in the hopes that these untrustworthy people will thereby be deterred from

\footnotetext{
${ }^{1}$ Samuel Pufendorf (1672) explains one such example, the invention of property rights, as follows: "[W]e may hence too discover the Falsity of that Vulgar Saying, Mine and Thine are the cause of all the Wars and Quarrels in the World. For on the contrary the Distinction of Mine and Thine was rather introduc'd to prevent all Contention."
} 
stealing. And it is well-known that most legal disputes are not resolved in court, but rather through pre-trial settlement (Bebchuk, 1984; Schweizer, 1989). Furthermore, hold-up by either or both parties causes the majority of settlements occur close to the trial date, indicating substantial rent-seeking (Spier, 1992).

We model conflict as a variation of the classic Tullock (1980) rent-seeking contest between two agents. Before the conflict arises, however, one participant may offer an ultimatumlike side payment to the other in order to avoid the contest. We show that when the side payment creates a binding commitment not to enter into the conflict, it is optimal for first-movers to pay off their opponents, resulting in an efficient but unequal division of the surplus. On the other hand, if the side payment does not create a binding commitment, first-movers should never offer a side payment, and second-movers who are offered a payment should always accept and then engage in conflict anyway.

Laboratory experiments confirm that binding side-payments reduce the costs of conflict relative to a baseline in which side-payments are not possible. However, roughly $30 \%$ of subjects reject these binding offers, and the mean observed offer is much closer to egalitarian than predicted. Furthermore, contrary to the theoretical equivalence of the baseline and non-binding cases, non-binding side-payments also improve efficiency, although not as much as in the binding case. With binding side-payments, $98 \%$ of efficiency gains result from avoiding conflicts. However, with non-binding side-payments, only $49 \%$ of the gains come from avoided conflicts. The remainder results from reduced conflict expenditures, suggesting that non-binding side-payments help reduce conflict in two ways, despite the incentives to exploit those who attempt to employ them.

The rest of the paper will be organized as follows: in section 2 , we briefly review the literature on conflicts and conflict resolution; in section 3 we detail our theoretical results; section 4 describes our experimental design, procedures and hypotheses; section 5 analyzes the results of the experimental sessions; and section 6 concludes.

\section{Literature Review}

The formal analysis of conflicts and conflict resolution originated with Schelling's (1960) masterpiece Strategy of Conflict. Schelling was one of the first to use game theoretical examples in raising important questions about problems of credible commitment in conflict resolution or 
conflict avoidance situations. One such example demonstrates that in the absence of well-defined property rights, conflicts may lead to extremely inefficient outcomes (Myerson, 2009). Hence this argument raises an important question about how rational agents can commit themselves to costly threats in order to avoid such inefficient equilibria.

Probably the most well-known example of inefficient conflicts is rent-seeking. In the original rent-seeking contest proposed by Tullock (1980), agents expend resources in order to win a prize. The winner is chosen probabilistically: the probability of winning equals the agent's expenditure divided by the sum of all agents' expenditures. The main message of the theoretical rent-seeking literature is that conflicts are very costly, and when they occur, they lead to wasteful expenditures of resources. ${ }^{2}$ Moreover, recent experimental literature reveals that conflicts are even more costly than predicted by the theory. In particular, it is well documented that in laboratory experiments subjects' expenditures are higher than the Nash equilibrium predictions in magnitudes ranging from $50 \%$ to $200 \%$. This over-competition is reduced with repetition of the experiment, but it does not disappear (Davis and Reilly, 1998; Potters et al., 1998; Sheremeta Forthcoming; Sheremeta 2010b). ${ }^{3}$

Given the high costs of conflict identified in the theoretical and experimental literature it is imperative to understand how conflicts can be reduced (Schelling, 1966). Some previous literature on conflict resolution describes several ways to reduce conflicts through contracting (Hirshleifer, 1995; Garfinkel and Skaperdas, 2000, 2007). In Hirshleifer's terminology, conflict can be reduced or eliminated through vertical or horizontal contracts. The former is best thought of as hierarchical domination of one party by another and the latter as contractual arrangement among equals (Garfinkel and Skaperdas, 2007). Ultimately, both solutions rely on binding contracts and credible commitments. The common underlying feature of conflict resolution models is that agents have bargaining powers that depend on their expected payoffs from the open conflict (Garfinkel and Skaperdas, 2000; Anbarci et al., 2002; Esteban and Sakovics,

\footnotetext{
${ }^{2}$ For a review of the theoretical literature see Konrad (2009). It is important to emphasize that some researchers have focused on cases in which the contest expenditures are not wasteful from the point of view of a third-party, e.g. contest designer, as in labor contests designed by firm owners to maximize employee effort (e.g. Lazear and Rosen, 1981, O’Keeffe, et al., 1984, Moldovanu and Sela, 2001). However, this interpretation relies on the presence of an external observer and the assumption that elicited effort contributes to something other than the contest itself. From the point of view of the individuals involved in the contest, expenditures may still remain wasteful.

${ }^{3}$ A number of studies have proffered explanations for overbidding in rent-seeking contests based on bounded rationality, misperception of probabilities and joy of winning (for a review see Sheremeta and Zhang, 2010).
} 
2006). ${ }^{4}$ Depending on relative bargaining power, conflicting parties can contract to avoid a potential conflict. Extensions of these theories have demonstrated that the feasibility of avoiding conflict may also depend on a number of other factors, such as the presence of a third party, the shadow of the future, or arms control (Che and Gale, 1998; Gavious et al., 2002; Frazier and Dixon, 2006). ${ }^{5}$

In the current study, we investigate whether conflicts can be avoided through sidepayments. Linster (1994) describes how side payments can eliminate or minimize rentdissipation in repeated Tullock contests. Jackson and Winkie (2005) show conditions under which the inherent inefficiency of various games (e.g. Cournot competition and the tragedy of the commons) can be mitigated with binding, strategy-contingent side payments. However, they emphasize that in equilibrium such side payments need not be efficient and may in fact create inefficiencies of their own. Muthoo (2004) describes a repeated game in which side payments expand the set of equilibria in which costly conflict can be avoided. Charness et al. (2007) provide experimental evidence that subjects use side payments in order to transform Prisoner's Dilemma games into coordination games. Jehiel and Moldovanu (1996) analyze auctions in which negative externalities are imposed on losing entrants and describe circumstances under which side payments can mitigate the losses from competition. Other studies of side-payments analyze such transfers in the context of bribery (Abbink et al., 2002; Abbink, 2004; Büchner et al., 2008).

Here we explore how side payments can create incentives to avoid costly conflict in oneshot Tullock contests. In our setting, one party can make an offer (binding or non-binding) to another party in order to avoid a conflict. The other party then chooses to accept or reject the offer. In the binding case, if the second-mover accepts the offer, then the prize goes to the firstmover; otherwise, the two parties engage in the standard Tullock contest. Thus, our binding case creates an environment in which subjects participate in an ultimatum bargaining game (e.g. Hoffmann and Spitzer 1985, Guth and Tietz 1990), where the disagreement point is a Tullock contest. As we will see later, this relationship to the ultimatum game has important implications

\footnotetext{
${ }^{4}$ Similar ideas are well known in the literature on territorial disputes among non-human animals (Parker, 1974).

5 Frazier and Dixon (2006) document that presence of a third party increases the probability of settlement. Schelling and Halperin (1961) argue that arms control treaties should result in less resource allocation towards military goods and, should conflict arise, lower destruction rates. Although recent theoretical findings by Che and Gale (1998) and Gavious et al. (2002), suggest that imposing caps (arms control) in the rent-seeking contest can surprisingly lead to increased spending.
} 
for subject behavior in this environment. Our more important innovation here comes in the nonbinding case, where the side-payment offer is (theoretically) non-binding. If the second-mover accepts the offer, he may still choose to participate in the Tullock contest in the second stage, even after he has received his side payment. Hence, at one extreme a cooperative second-mover may choose to convert the conflict game into an ultimatum game by accepting a side-payment and then choosing not to enter, and at the other extreme an untrusting first-mover can unilaterally assure that bargaining results in the disagreement point. In the next section we analyze this game theoretically.

\section{Theoretical Model}

Consider a potential conflict situation between two players for a prize valued at $v$ by both players. We define the conflict situation in two sequential stages, the bargaining stage and the conflict stage. In the bargaining stage, player 1 can offer a side payment $s$ to player 2 in order to avoid the conflict stage. If player 2 accepts the side payment offer, then the game ends with neither player advancing to the conflict stage. Player 2 receives a payoff of $\pi_{2}=s$ while player 1 receives a payoff of $\pi_{1}=v-s$. However, if in the bargaining stage, player 2 rejects the side payment offer, then both players advance to the conflict stage in which they compete in an allpay contest to determine who receives the prize. ${ }^{6}$

We model the conflict stage according to Tullock's (1980) rent-seeking contest. In such a contest, two risk-neutral players make irreversible expenditures $e_{1}$ and $e_{2}$ in an attempt to receive a prize value $v$. Player $i$ 's probability of winning is defined by a contest success function (Skaperdas, 1996):

$$
p_{i}\left(e_{1}, e_{2}\right)=e_{i} /\left(e_{1}+e_{2}\right) \text {. }
$$

The expected payoff for a risk-neutral player $i$ is equal to the probability of player $i$ winning, $p_{i}\left(e_{1}, e_{2}\right)$, times the prize valuation, $v$, minus contest expenditure, $e_{i}$.

$$
E\left(\pi_{i}\right)=p_{i}\left(e_{1}, e_{2}\right) v-e_{i}
$$

By differentiating (2) and solving the best response functions simultaneously, we obtain the following unique Nash equilibrium expenditure levels for players 1 and 2:

\footnotetext{
${ }^{6}$ It is important to emphasize that the results of our model may change if players first choose to invest in armaments (i.e., make bids first) and only then enter the bargaining stage (i.e., offer a contract). Moreover, we could alter the results by introducing collateral damage due to conflict, such as a partial destruction of the prize (Garfinkel and Skaperdas, 2000; Skaperdas, 2006).
} 


$$
e_{1}^{*}=e_{2}^{*}=v / 4 \text {. }
$$

Given the equilibrium expenditures (3), the expected payoffs of players 1 and 2 from the contest are:

$$
E\left(\pi_{1}{ }^{*}\right)=E\left(\pi_{2}{ }^{*}\right)=v / 4 \text {. }
$$

Clearly, the contest is socially costly because all resources invested in the conflict stage are wasted. It is also individually costly to the loser, so both players, having complete knowledge of the game's structure and its incentives, may prefer to avoid the conflict stage by offering side payments in the bargaining stage. However, for a side payment to be acceptable to its recipient, the amount of the transfer must at least provide compensation equal to the expected payoff from entering the conflict. Thus, to prevent player 2 from entering the conflict, player 1 should optimally offer a side payment equal to $s^{*}=E\left(\pi_{2}{ }^{*}\right)=v / 4$, and since such a side payment provides player 2 with the same payoff she expects to earn in the conflict, she should accept the side payment, thereby avoiding the conflict. In such a case, player 1's equilibrium payoff is $\pi_{1}{ }^{*}=v$ $s^{*}=3 v / 4$, player 2's payoff is $\pi_{2}{ }^{*}=s^{*}=v / 4$, and the total surplus is $\Pi^{*}=\pi_{1}{ }^{*}+\pi_{2}{ }^{*}=v$. Notice that side payments are efficient since by avoiding the conflict stage, the players waste no resources in the contest. However, payoffs with side payments are far from equitable; the payoff to player 1 is three times higher than that of player 2 .

The argument thus far was based on the assumption that side payment contracts in the bargaining stage are binding, i.e. if player 2 accepts the side payment, then she renounces any further claim to the prize and may not choose to enter the conflict stage. However, we now ask how the result changes when the side payment creates a non-binding contract. When the side payment is non-binding, player 2 chooses simultaneously in the bargaining stage whether to accept the side payment $s$ and also whether to enter the conflict stage. Since playing the equilibrium strategy in the contest yields an additional expected payoff of $E\left(\pi_{2}{ }^{*}\right)=v / 4$, player 2 should always accept any side payment and then still choose to enter the conflict stage. Thus, knowing that player 2 cannot be dissuaded from conflict in the bargaining stage, player 1 will never offer a side payment, i.e. $s^{*}=0$, and the game will always reach the conflict stage. As a result, there is efficiency loss due to resource expenditures in the contest. ${ }^{7}$ Thus, equilibrium

\footnotetext{
${ }^{7}$ Here we assume that a side payment is a sunk cost for player 1 . Thus, when player 2 accepts the side payment in the bargaining stage, player 1 cannot reclaim it in the conflict stage. However, if the side payment is added to the prize value and can be reclaimed in the conflict stage then a non-binding contract becomes effectively binding.
} 
total surplus in the non-binding case is $\Pi^{*}=E\left(\pi_{1}{ }^{*}\right)+E\left(\pi_{2}{ }^{*}\right)=v / 2$, equivalent to the outcome in the original rent-seeking contest without side payments. As before, the loss of the surplus comes from expenditures in the conflict, i.e. $e_{1}{ }^{*}=e_{2}{ }^{*}=v / 4$.

Hence, our theory provides two very distinct predictions depending on the form of the side-payment contract employed in the bargaining stage. Side payments that bind recipients not to enter the conflict stage should always be offered at a rate equal to the expected value from the contest, and they should always be accepted, thereby eliminating conflict and its attendant efficiency losses. On the other hand, if the contract is non-binding, then no side payment should ever be offered since the recipient will always accept and then enter the conflict anyway. The results of our model stress the importance of rule of law and paint a bleak picture of prospects for reducing conflict in the absence of mechanisms for contract enforcement. ${ }^{8}$ When contracts cannot be enforced and parties may renege (as is frequently the case in many societies), our model predicts that conflict over resources will be ubiquitous and costly. ${ }^{9}$ To compare the predictions of the theory to the behavior of motivated human subjects, we turn to a laboratory experiment.

\section{Experimental Design and Procedures}

We employ three treatments to test the predictions of our theory: Baseline, Binding, and Non-Binding. The outline of the experimental design and the theoretical predictions for each treatment are shown in Table 1. In the Baseline treatment, players 1 and 2 are exogenously placed into a conflict situation, where they expend resources in order to receive a prize value $v=$ 60. This treatment replicates previous experimental work on one-shot Tullock contests and provides us a basis for comparison of our new treatments' effects on subject behavior. The equilibrium prediction in the Baseline treatment is that both players will expend 15 and each will receive on average a payoff of 15 .

The other two treatments, Binding and Non-Binding introduce the bargaining stage to the game, prior to the conflict stage. In the bargaining stage of the Binding treatment, player 1

\footnotetext{
${ }^{8}$ We note that enforcement mechanisms usually have costs of their own that we do not model here, and if those costs are sufficiently high, not even binding contracts can eliminate conflict.

${ }^{9}$ Recall that previous experiments have shown that individuals display a persistent tendency to over-invest in conflict, so the absence of enforcement may be even more costly than our model suggests.
} 
(hereafter the Proposer) can make a binding side payment offer $s$ to player 2 (hereafter the Responder). If the Responder accepts the offer, then she receives a payoff of $s$ and the Proposer receives the payoff of $60-s$. The equilibrium prediction in the Binding treatment is that the Proposer will make an offer of $s=15$ and the Responder will accept the side payment, thereby avoiding the conflict. Finally, in the Non-Binding treatment the side payment offer $s$ by the Proposer is non-binding, i.e. the Responder chooses simultaneously whether to accept the side payment and also whether to enter the conflict stage. Hence, the Responder may accept a side payment and nevertheless enter the conflict. Since the side payment contract is non-binding, the equilibrium offer of the Proposer is $s=0$. In this case conflict ensues with probability 1 . The outcome is identical to the Baseline game with no bargaining stage.

However, previous experimental work in bargaining (Hoffmann and Spitzer 1985, Guth and Tietz 1990) and conflicts (Davis and Reilly, 1998; Potters et al., 1998) suggests that some aspects of the theoretical predictions are not likely to be borne out by the data. In particular, conflict, should it occur, is likely to be more costly than predicted by the theory. Hence, the results in the bargaining stage could be impacted in a number of ways. For example, knowing that conflict is unlikely to yield a large expected payoff, Responders in the Binding treatment may be willing to accept side-payments even lower than predicted by the theory. On the other hand, if Responders frequently reject offers close to their indifference point (as is observed in many Ultimatum games), then Proposers might increase their offers to Responders to induce higher acceptance rates.

Each experimental session consisted of 30 periods of a single treatment in which subjects were randomly and anonymously re-matched in each period. In each of the side-payment treatments, subjects were randomly assigned the initial role of either Proposer or Responder, where the Proposer made either a binding offer (Binding treatment) or a non-binding offer (NonBinding treatment) to the Responder in the bargaining stage. Subjects remained in this role for the first 15 periods of the session, and then all Proposers became Responders and vice versa for the final 15 periods. At the end of each experimental session, subjects completed a brief demographic survey. To reinforce the one-shot incentives of the game, subjects knew beforehand that we would select five of the 30 periods for payment using a bingo cage; subjects' earnings from these five periods were added to or subtracted from an initial endowment of 600 (which we described as a participation fee). We converted endowments to USD at a rate of $30=\$ 1$, and 
subjects were paid privately in cash and dismissed from the experiment. Sessions lasted roughly an hour each.

Subjects $(44 \%$ male, average age $=20)$ were recruited at random from the undergraduate student body of a private university in the United States to participate in 9 experimental sessions with 12 subjects each. ${ }^{10}$ Subjects sat at, and interacted via, visually isolated computer terminals, and instructions were read aloud by the experimenter as subjects followed along on paper. Subjects received their initial endowments of 600 (\$20) for arriving to the experiment on time and received their earnings in cash privately at the end of each 90-minute session. The average experimental earnings, including the $\$ 20$ participation fee, were $\$ 22.00$, ranging from a low of $\$ 15.75$ to a high of $\$ 26.75$. No subject participated more than once, and no subject had prior experience with a similar experimental environment. Instructions for the Non-Binding treatment are included in an appendix. Instructions for the other treatments are available upon request.

\section{Results}

\subsection{Surplus}

We will proceed by exploring the relation between our experimental data and the theoretical predictions listed in Table 1. Then, where our observations make it necessary, we will attempt to explain deviations from the theory and differences between the treatments. For all statistical analysis we use panel regressions with subject specific random effects. In all estimations we control for learning (of which we find scant evidence), order of play, and session effects. First, we compare the treatments to the theory by total surplus produced and individual conflict expenditures.

Finding 1: In all three treatments, surplus is smaller than predicted by the theory. However, both Binding and Non-Binding side-payments increase surplus relative to the Baseline; although, the effect is much larger for the Binding treatment.

Table 2 displays summary statistics for the three treatments. Theory predicts a total surplus of 30 for each pair in the Baseline, 60 in the Binding, and 30 in the Non-Binding treatment (see Table 1). Observe that in the Baseline treatment, the average joint surplus for the two individuals is only 1.4 , which is significantly lower than the theoretical surplus of 30 (p-

\footnotetext{
${ }^{10}$ There were only 10 subjects in two of our baseline sessions, for a total of 104 subjects in all sessions.
} 
value < 0.01). ${ }^{11}$ In the Binding and Non-Binding treatments, the average surplus is 42.8 and 18.7, respectively, which are both lower than the theoretical predictions of 60 and 30 (p-values < 0.01). As expected, the greatest surplus is produced by the employment of Binding side-payment contracts. However, surprisingly, Non-Binding side-payments also substantially increase surplus relative to the Baseline. ${ }^{12}$

\subsection{Conflict Expenditures and Sources of Efficiency Improvement}

Having established differences between the three treatments, we look deeper into the data to explain the sources of efficiency improvement in the Binding and Non-Binding cases. Figure 1 displays histograms with Gaussian kernel density estimations detailing the distribution of conflict expenditure by treatment, conditional on participation in the conflict. ${ }^{13}$ In the Baseline treatment, average individual conflict expenditure is 29.3. In the side-payment treatments with Binding and Non-Binding contracts, average conflict expenditures are 26.5 and 24, respectively. ${ }^{14}$

These observations replicate previous experimental results demonstrating that conflict is extremely inefficient and costly. It is important to emphasize that, although subjects in all treatments fight with greater intensity than theory predicts, conflict expenditures are lower in the

\footnotetext{
${ }^{11}$ To support these conclusions we estimate simple panel regressions separately for each treatment, where the dependent variable is the surplus (payoff) and the independent variables are a constant, a period trend, and a dummy variable to control for role-switching in period 15. The models included a random effects error structure, with the individual subject as the random effect, to account for the multiple decisions made by individual subjects. The standard errors were clustered at the session level. Based on a standard Wald test conducted on estimates of each model, we found that surplus (payoff) in the Baseline, Binding, and Non-Binding treatment is significantly lower than predicted (all p-values < 0.01 ).

${ }^{12}$ We estimated several random-effect regressions of surplus (payoff) on the treatment dummy variables, a time trend, and a dummy variable to control for role-switching in period 15. All three pair-wise comparisons indicate that the surplus is the Binding treatment is higher than the surplus in the Non-Binding and Baseline (both p-values < 0.01). Similarly, the surplus in the Non-Binding treatment is significantly higher than the surplus in the Baseline treatments ( $\mathrm{p}$-value $<0.01$ ). In all regressions, a random effects error structure accounted for the multiple decisions made by individual subjects and standard errors were clustered at the session level to account for session effects.

13 All graphics were created using R: A Language and Environment for Statistical Computing (2010) and a contributed package (Warnes, Bolker and Lumley 2008). We employ the standard rule-of-thumb from Scott (1992) to select our kernel bandwidth.

${ }^{14}$ Note that the distribution of expenditures is flatter in the Baseline and Non-Binding treatments than in the Binding treatment, indicating that subjects make less variable bids after rejecting a binding contract. This observation is consistent with Eriksson et al. (2009) who find, in a rank-order tournament, that the between-subject variance is lower when subjects self-select into the tournament than when the tournament is imposed exogenously.
} 
Binding and Non-Binding treatments than in the Baseline. ${ }^{15}$ However, taken alone, these reductions in conflict expenditure are insufficient to account for observed efficiency improvements. In the side payment treatments, increased surplus is also due to lower rates of entry into conflict. To identify the relative impact of these two effects, we decompose the sources of efficiency improvement.

Table 3 displays the average surplus gains in each of the side-payment treatments relative to the Baseline and shows what portion of those gains are due to non-entry into conflict and what portion are due to conflict de-escalation. Let $\Pi_{k}$ be the total average surplus earned in treatment $k, k \in\{$ Baseline, Binding, Non-Binding $\}$, where $\Pi_{k}=E\left(\pi_{1}\right)+E\left(\pi_{2}\right)$. Let $\Delta \Pi_{k}=\Pi_{k}-\Pi_{\text {Baseline }}$ be the average surplus gain in treatment $k$ relative to the Baseline. Now, let $P_{k}$ be the probability of avoiding conflict in treatment $k$, and recall that the average available surplus is $v=60$. The average surplus gain from non-entry in treatment $k$ is defined as $v P_{k}$, and the percentage of gains due to non-entry is $\left(v P_{k} / \Pi_{k}\right) \times 100 \%$.

Finding 2: In the Binding treatment, $98 \%$ of the increase in surplus is due to reduced entry into conflict. However, in the Non-Binding treatment, only $49 \%$ of the gains are due to reduced entry.

The Binding treatment induces $68 \%$ of pairs to avoid conflict; hence almost all of the surplus gains (98.6\%) result from decisions not to enter the conflict stage. On the other hand, the gains in the Non-Binding treatment come both from reduced entry (48.6\%) and from reduced expenditures in conflict (51.4\%). The ability to employ Non-Binding side payments induces pairs to avoid conflict $14 \%$ of the time because some Responders make side payments binding by choosing not to enter the conflict stage. However, Non-Binding payments also lead subjects to reduce their conflict expenditures.

Why do subjects in the Non-Binding treatment reduce their expenditures in conflict? There are a number of competing hypotheses. For example, if the offers serve as cooperative signals by Proposers to Responders, one would expect that there is a negative correlation between the size of the offer and the amount of conflict expenditure for both parties. If Proposers set aside a fixed budget that they are willing to allocate to conflict, then again we would expect

\footnotetext{
15 Based on the random-effect regression analysis, the expenditures in the Baseline are significantly higher than in the Non-Binding and Binding treatments ( $\mathrm{p}$-value $=0.07$ and $\mathrm{p}$-value $=0.07$ ). However, there is no significant difference between the Non-Binding and Binding treatments (p-value $=0.42)$.
} 
the size of their offer to be negatively correlated with their conflict expenditures, or similarly, if Responders treat Proposers' offers as subsidies to their conflict investment, then one would expect a positive correlation between offers and Responders' expenditures. On the other hand, if Proposers fall prey to the sunk cost fallacy, one would expect a positive correlation between offers and Proposers' expenditures.

Table 4 reports average non-zero offers and associated conflict expenditures in the NonBinding treatment, conditional on the decision to accept or reject the offer. In the cases in which the Responder chooses to accept a non-zero offer (mean offer $=14.9$ ) and also to enter the conflict, we find that the average expenditures by Proposer and Responder are 24.9 and 22.9. However, for rejected non-zero offers (mean offer $=9.1$ ), average conflict expenditures increase to 26.8 for Proposers and 28.6 for Responders. This gives some credence to the signaling hypothesis. Furthermore, a regression of conflict expenditures on offers, controlling for whether the Responder accepted the offer, shows a significant negative effect of offer size for Proposers (p-value < 0.01), which also supports the signaling hypothesis and, potentially, the budgeting hypothesis. ${ }^{16}$ However, we find no significant effect of offer size on expenditures for Responders (p-value $=0.29)$. It may be that more than one of the aforementioned effects is operating simultaneously and that in some cases the effects are offsetting. Perhaps eliciting all decisions simultaneously via the strategy method would better disambiguate these hypotheses because signaling would no longer be possible. We suggest this for future research but do not explore this possibility here. Next we analyze the conditions under which pairs in the side payment treatments were able to avoid conflicts.

\subsection{Accepted and Rejected Offers}

Table 5 displays information about the number of offers, rejections, and conflicts avoided in the Binding and Non-Binding treatments. A number of interesting observations emerge. First, in both treatments, subjects reject roughly $30 \%$ of offers in the first stage. Second, in the Binding treatment, every Proposer made a positive offer to the Responder, but in the Non-Binding treatment, Proposers offered the predicted amount of zero in only 170/540 (31.5\%) of the first stage decisions. Finally, although theoretically there is no incentive to do so, Responders in the

\footnotetext{
${ }^{16}$ As before, we estimate random effects by subject and cluster standard errors by session.
} 
Non-Binding treatment reject 43/370 (11.6\%) of Proposers' non-zero offers. All of these facts help us to explain the gains from side payments, so to flesh them out we look more deeply into the distribution of offers and the impact of offer size on Responders' acceptance and entry decisions.

To understand how and when subjects use side payments to avoid conflicts we examine the characteristics of offers and their impact on Responders' decisions to enter the conflict stage. Figure 2 displays histograms of offers in the Binding and Non-Binding treatments. Similarly, Table 6 contains summary statistics about the offers in the two treatments with side-payments. We calculate the average offer, average accepted offer, average offer that led Responders not to enter (in the Non-Binding treatment), and average rejected offer. First, we compare the average offer in the Binding and Non-Binding treatments.

Finding 3: Both the average and the average accepted offers in the Binding treatment are significantly higher than in the Non-Binding treatment. However, offers in both treatments are higher than predicted by the theory.

Table 6 indicates that the average (accepted) offer in the Binding treatment is 26.2 (27.7), or $75 \%(85 \%)$ greater than the theoretical prediction of 15 , and the average (accepted) offer in the Non-Binding treatment is 11 (14.3), though the theory predicts offers of $0 .{ }^{17}$ Furthermore, the average offer in the Binding treatment is significantly higher than in the Non-Binding treatment. ${ }^{18}$ Recall that in the Non-Binding treatment, subjects can still enter the conflict even after accepting the offer. Therefore, the third row of Table 6 reports the average accepted offer in the Non-Binding treatment, conditional on the Responder choosing not to enter. These instances represent the cases in which subjects in the Non-Binding treatment chose to make the side payments binding. Perhaps surprisingly, as with unconditional accepted offers, the mean accepted offer of 27.7 in the Binding treatment is significantly higher than the mean accepted offer, conditional on non-entry, of 24.8 in the Non-Binding treatment. ${ }^{19}$ One explanation is that

\footnotetext{
17 These offers are significantly higher than the predicted offers based on the estimation of panel regressions separately for each treatment (all p-values < 0.01 ).

${ }^{18}$ As before, a random effects error structure accounted for the multiple decisions made by individual subjects and standard errors were clustered at the session level to account for the session effects.

${ }^{19}$ The accepted offer in the Binding treatment is significantly higher than both conditional and unconditional accepted offer in the Non-Binding based on the estimation of panel regressions, with offer being dependent variable and treatment dummy and period trend being independent variables ( $\mathrm{p}$-value $<0.01$ and $\mathrm{p}$-value $=0.02$, respectively for unconditional and conditional accepted offers).
} 
the average unconditional offer in the Binding treatment is 26.2, and in the Non-Binding treatment it is only 11.0 (see Table 2). Therefore, lower average unconditional offers in the NonBinding treatment may lower subjects' expectations about the perceived appropriate conflictavoiding offer.

Although theory predicts the directional difference between the treatments, subjects in both treatments offer more than expected. The regularity of excessive (relative to the theory) offers may indicate peculiarities in the acceptance and rejection behavior of Responders. By examining rejection rates we can further explore these possibilities.

Finding 4: Contrary to theoretical predictions, more than $30 \%$ of offers in the Binding treatment are rejected, with an average rejected offer of 23.3. However, in weaker support of the theory, the probability of accepting the offer is increasing in the offer size.

The theoretical prediction for the Binding treatment is that any offer greater than or equal to 15 should be accepted because such offers exceed the expected gains from conflict. A weaker implication of the theory is that the probability of accepting the offer will increase with the amount of the offer, and indeed, we find support for this claim: an offer between 0 and 20 is accepted with the probability of 0.17 , an offer between 20 and 40 is accepted with the probability of 0.69 , and an offer between 40 and 60 is accepted with the probability of 1.00. Nevertheless, Table 5 reports that more than $30 \%$ of offers are rejected in the Binding treatment. The average rejected offer is 23.3 (Table 5), which is 55\% larger than the offer predicted by the theory. Hence, the rejection rate in the Binding treatment cannot be explained by insufficient offers relative to the theoretical predictions. More likely, high offers result from the (expectation and experience of) relatively high rejection rates, which we observe despite the fact that the average payoff from conflict is negligible and much lower than the theoretical payoff of 15 (i.e. 0.7 in the Baseline, 3.5 in the Binding treatment, and 6 in the Non-Binding treatment). ${ }^{20}$

What explains the high rejection rate and the fact that subjects frequently reject offers larger than those predicted by the theory? First, we note that individual differences play a significant role in Binding treatment rejection behavior. For example, we observe a strong negative correlation between individuals' offers when in the role of Proposer and their rejection rates as Responders $(\mathrm{r}=-0.38$, p-value $=0.02)$. However, this fact begs the question of why some subjects prefer conflict to settlement. Previous experimental studies of contests have

\footnotetext{
${ }^{20}$ We calculate these averages by subtracting the mean conflict expenditures from the value of the prize.
} 
demonstrated that subjects may receive utility from the simple fact of victory. In Sheremeta (2010a; 2010b) subjects expend resources in lottery contests where the prize is worth nothing, and the amount of that expenditure is equal to the amount by which they overbid relative to the theory in other variations of the game where the prize has positive value. Furthermore, in the classic "Dollar Auction" from Shubik (1971), individuals frequently bid and pay more than one dollar for a dollar prize. Hence if subjects value victory then they may choose to engage in conflict when it would be more efficient to accept the Proposer's offer. ${ }^{21}$

A second explanation can be found in the aforementioned similarities between the bargaining stage of our game and the standard ultimatum game, which we argue induces similar behavioral tendencies. Replication upon replication has demonstrated a persistent tendency of subjects to "irrationally" reject offers in ultimatum games; however, the debate about the source of these rejections persists (e.g. Guth and Tietz 1990; Murnighan 2008). For example, in a wellknown study, Hoffman et al. (1994) demonstrate that allowing subjects to earn the right to be first-movers in an ultimatum game both diminishes offers and decreases the rate of rejection. Since in our experiment the roles of Proposer and Responder are randomly assigned (and not earned or in any way tied to performance) subjects may be unwilling to accept offers that deviate from their sense of propriety. In other words, high rejection rates could be a result of spiteful responses to the perceived excessive exploitation of an unearned right. On the other hand, subjects may make their rejections on the basis of preferences over the social distribution of surplus. If, for example, subjects are inequality averse, then they may be unwilling to accept offers that lead to unequal outcomes regardless of whence comes the right. Future research should focus on how to test these hypotheses separately. However, even more puzzling and intriguing is the high rejection rate in the Non-Binding treatment.

Finding 5: Contrary to theoretical predictions, $28 \%$ of offers in the Non-Binding treatment are rejected, and the average rejected offer equals 2.4. Moreover, the probability of accepting the offer and the probability of choosing to avoid conflict are increasing in offer size.

Although the theoretical prediction for the Non-Binding treatment is that any offer of any size should be accepted, Table 5 reports that $28 \%$ of all offers are rejected. Moreover, the

\footnotetext{
${ }^{21}$ More surprising are the few instances in which subjects reject theoretically acceptable offers and expend so much in conflict that their earnings (assuming they win) are less than they would have received by accepting the offer.
} 
probability of accepting the offer and avoiding conflict are increasing in the offer size: when the offer is between 0 and 20 the probabilities of acceptance and conflict avoidance are 0.66 and 0.09 , when the offer is between 20 and 40 these probabilities are 0.96 and 0.33 , and when the offer is between 40 and 60 these probabilities are 1.00 and 0.46

The average rejected offer in the Non-Binding treatment is 2.4 (Table 6). There are a number of possible explanations for such behavior. For example, knowing that they intend to enter the second stage (for whatever reason), subjects that value honesty may choose not to accept a transfer that they believe was sent in good faith with the goal of circumventing conflict. Similarly a sense of nobility or desire for a "fair" fight would lead to rejections if accepting a transfer is perceived as creating an imbalance of power, or one might also rationalize the behavior by postulating inequality aversion.

Another explanation of our data is that rejections are intended as a form of communication or signaling. The modal rejected offer is 0 and the mean rejected offer is 2.4 suggesting that most observed rejections are intended to be expressive. Subjects may reject positive (but low) offers in hopes of signaling to others that for a sufficient offer, they would be willing to avoid a conflict. ${ }^{22}$ While an individual should be economically indifferent between accepting and rejecting an offer of 0 , a rejection may constitute cheap talk through which a Responder can signal displeasure with the offer. We find weak support for this hypothesis, as subjects who reject offers of 0 expend 25.3 on average in the conflict stage, which is higher (although not significantly) than the expenditure of 23.5 by subjects who accept offers of 0 .

As in the Binding treatment, we note that individual differences play an important role in rejection behavior. For example, in the Non-Binding treatment, we observe a significant and positive correlation between subjects' mean offers as Proposers and their rejection rates as Responders $(\mathrm{r}=0.40, \mathrm{p}$-value $=0.02)$ indicating that some subjects maintain a tendency to seek and signal cooperative intent throughout the session. ${ }^{23}$ This interpretation finds additional support in the positive and significant correlation between subjects' offers as Proposers and their rate of non-entry as Responders $(r=0.44$, $\mathrm{p}$-value $<0.01)$.

\footnotetext{
${ }^{22}$ It is interesting that even with random re-matching, which guarantees that such a signal is extremely noisy, we nevertheless observe that in $14 \%$ of cases these subjects receive sufficient offers and conflict is averted. This suggests that endogenous or exogenous sorting and/or repeat play may further reduce the cost of conflicts with nonbinding side payments. Evidence of such effects for prisoner's dilemmas and trust games already exists (e.g. Kahn and Murnighan 2008; McCabe et al. 2007).

23 Note that the effect in the Non-Binding treatment is exactly the opposite of that in the Binding treatment.
} 


\section{Conclusion}

In this paper, we develop and test a theory of conflict resolution via side payments. In our two-stage game, two agents interact in a conflict over a valuable resource. In the first stage, one agent may make an ultimatum-style offer to the other agent who then chooses to accept or reject the offer. In one case, accepting the offer binds the second-mover to not engage in a lottery contest for the resource, and in the other case, second-movers choose to accept or reject the offer and choose simultaneously whether to enter the conflict. While the theory predicts that only binding side-payment contracts will be able to eliminate conflicts (i.e. the first stage offers that bind their recipients not to engage in conflict), we find that even in cases in which individuals have no reason to offer side-payments to avoid a conflict, the possibility of transfers reduces the frequency and intensity of conflict. While binding contracts are not as effective as predicted by the theory and while subjects who engage in conflict still overinvest, we find that non-binding contracts are more effective than predicted and provide some measure of increased security relative to a baseline without the possibility of transfers. In a world in which recourse to exogenous enforcement mechanisms is frequently a luxury (and just as frequently, impossible), this result suggests that the prospects for reducing conflict between individuals and nations is not as bleak as the rational actor model suggests.

One additional virtue of this project is that the results suggest as many new questions as they answer. In addition to the puzzles mentioned above, one could ask, for example, under what conditions would the efficiency benefits of the Non-Binding treatment be eliminated? Or how could Non-Binding contracts be made as efficient as Binding ones? How would asymmetries in power affect the outcomes? How would communication impact the rate and intensity of conflict? How would subjects behave in a repeated version of the game with the same counterpart, or in a one-shot version of the game? We leave these questions open for future research. 


\section{References}

Abbink, Klaus. 2004. "Staff Rotation as an Anti-corruption Policy: an Experimental Study." European Journal of Political Economy, 20: 887-906.

Abbink, Klaus, Bernd Irlenbusch, and Elke Renner. 2002. "An Experimental Bribery Game." Journal of Law, Economics and Organization, 18(2): 428-454.

Anbarci, Nejat, Stergios Skaperdas, and Constantinos Syropoulos. 2002. "Comparing Bargaining Solutions in the Shadow of Conflict: How Norms Against Threats Can Have Real Effects." Journal of Economic Theory, 106(1): 1-16.

Bebchuk, Lucian A. 1984. "Litigation and Settlement under Imperfect Information." RAND Journal of Economics, 15: 404-415.

Büchner, Susanne, Andreas Freytag, Luis Gonzalez, and Wener Güth. 2008. "Bribery and Public Procurement - An Experimental Study.” Public Choice, 137: 103-117.

Charness, Gary, Guillame R. Frechette, and Cheng-Zong Qin. 2007. "Endogenous Transfers in the Prisoner's Dilemma Game: An Experimental Test of Cooperation and Coordination." Games and Economic Behavior, 60(2): 287-306.

Che, Yeon-Koo and Ian L. Gale. 1998. "Caps on Political Lobbying." American Economic Review, 88(3): 643-651.

Davis, Douglas and Robert Reilly. 1998. Do Many Cooks Always Spoil the Stew? An Experimental Analysis of Rent Seeking and the Role of a Strategic Buyer." Public Choice, 95: 89-115.

Eriksson, Tor, Sabrina Teyssier, and Marie-Claire Villeval. 2009. "Self-selection and the Efficiency of Tournaments." Economic Inquiry, 47(3): 530-548.

Esteban, Joan. M. and Jozsef Sakovics. 2006. "A Theory of Agreements in the Shadow of Conflict." Unpublished manuscript, University of Edinburgh, Edinburgh, UK.

Frazier, Derrick V. and William J. Dixon. 2006. "Third-Party Intermediaries and Negotiated Settlements, 1946-2000." International Interactions, 32(4): 385-408.

Garfinkel, Michelle. R. and Stergios Skaperdas. 2000. "Conflict without Misperceptions or Incomplete Information - How the Future Matters." Journal of Conflict Resolution, 44(6), 793-807.

Garfinkel, Michelle. R. And Stergios Skaperdas. 2007. "Economics of Conflict: An Overview" in Handbook of Defense Economics, ed. Todd Sandler and Keith Hartley, 649-710. New York, NY: Elsevier. 
Gavious, Arieh, Benny Moldovanu and Aner Sela. 2002. "Bid Costs and Endogenous Bid Caps." RAND Journal of Economics, 33(4): 709-722.

Guth, Werner and Reinhald Tietz. 1990. "Ultimatum Bargaining Behavior: A Survey and Comparison of Experimental Results." Journal of Economic Psychology, 11(3): 417-449.

Hirshleifer, Jack. 1995. "Theorizing about Conflict" in Handbook of Defense Economics, ed. Todd Sandler and Keith Hartley, 165-190. New York, NY: Elsevier.

Hoffman, Elizabeth and Matthew Spitzer. 1985. "Entitlements, Rights, and Fairness: an Experimental Examination of Subjects' Concepts of Distributive Justice." Journal of Legal Studies, 15: 254-297.

Hoffman, Elizabeth, Kevin McCabe, Keith Shachat, and Vernon Smith. 1994. "Preferences, Property Rights, and Anonymity in Bargaining Games." Games and Economic Behavior 7: $34-380$.

Jackson, Matthew. O. and Simon Wilkie. 2005. "Endogenous Games and Mechanisms: Side Payments among Players." Review of Economic Studies, 72(2): 543-566.

Jehiel, Phillipe and Benny Moldovanu. 1996. "Strategic Nonparticipation." RAND Journal of Economics, 27(1): 84-98.

Kahn, Lawrence M. and J. Keith Murnighan. 2008. "Payoff Uncertainty and Cooperation in Finitely-Repeated Prisoner's Dilemma Games," in Handbook of Experimental Economics Results, Vol. 1, ed. Charles R. Plott and Vernon L. Smith, 598-606. New York, NY: Elsevier.

Katz, Eliakim, Samuel Nitzan and Jacob Rosenberg. 1990. "Rent-seeking for Pure Public Goods." Public Choice, 65: 49-60.

Konrad, Kai. A. 2009. Strategy and Dynamics in Contests. New York, NY: Oxford University Press.

Lazear, Edward P. and Sherwin Rosen. 1981. "Rank-Order Tournaments as Optimum Labor Contracts.” Journal of Political Economy, 89(5): 841-864.

Linster, Bruce G. 1994. "Cooperative Rent-Seeking.” Public Choice, 81: 23-34.

McCabe, Kevin A., Mary L. Rigdon, and Vernon L. Smith. 2007. "Sustaining Cooperation in Trust Games,” Economic Journal, 117(522): 991-1007.

Modolvanu, Benny and Aner Sela. 2001. "The Optimal Allocation of Prizes in Contests." American Economic Review, 91(3): 542-558. 
Murnighan, J. Keith. 2008. "Fairness in Ultimatum Bargaining," in Handbook of Experimental Economics Results, Vol. 1, ed. Charles R. Plott and Vernon L. Smith, 436-453. New York, NY: Elsevier.

Muthoo, Abhinay. 2004. "A Model of the Origins of Basic Property Rights." Games and Economic Behavior, 49(2): 288-312.

Myerson, Roger. B. 2009. "Learning from Schelling's Strategy of Conflict." Journal of Economic Literature, 47(4): 1109-1125.

O'Keeffe, Mary, W. Kip Viscusi and Richard J. Zeckhauser. 1984. "Economic Contests: Comparative Reward Schemes." Journal of Labor Economics, 2(1): 27-56.

Parker, G.A. 1974. "Assessment Strategy and the Evolution of Fighting Behavior." Journal of Theoretical Biology, 47(1): 223-243.

Potters, Jan C. Casper G. De Vries, and Frans Van Linden. 1998. "An Experimental Examination of Rational Rent Seeking.” European Journal of Political Economy, 14: 783-800.

Pufendorf, Samuel. (1672) Of the Law of Nature and Nations: Eight Books. New Jersey: The Lawbook Exchange, Ltd., 2005.

R Development Core Team. (2010) R: A language and environment for statistical computing. Vienna: R foundation for statistical computing. http://www.R-project.org

Schechter, Laura. 2007. "Theft, Gift-giving, and Trustworthiness: Honesty Is Its Own Reward in Rural Paraguay.” American Economic Review, 97(5): 1560-1582.

Schelling, Thomas. 1960. The Strategy of Conflict. Cambridge, MA: Harvard University Press.

Schelling, Thomas. 1966. Arms and Influence. New Haven, CT: Yale University Press.

Schelling, Thomas, and Morton Halperin. 1961. Strategy and Arms Control. New York, NY: 20th Century Fund.

Schweizer, U. 1989. "Litigation and Settlement under Two-Sided Incomplete Information." Review of Economic Studies, 56(1): 163-178.

Scott, David W. 1992. Multivariate Density Estimation: Theory, Practice, and Visualization. New York, NY: Wiley.

Sheremeta, Roman M. Forthcoming. "Contest Design: An Experimental Investigation." Economic Inquiry.

Sheremeta, Roman M. 2010a. "Expenditures and Information Disclosure in Two-Stage Political Contests." Journal of Conflict Resolution, 54, 771-798 
Sheremeta, Roman M. 2010b. "Experimental Comparison of Multi-Stage and One-Stage Contests." Games and Economic Behavior, 68(2): 731-747.

Sheremeta, Roman. M. and JingJing Zhang. 2010. "Can Groups Solve the Problem of OverBidding in Contests?" Social Choice and Welfare, 35(2): 175-197.

Shubik, Martin. 1971. "The Dollar Auction Game: A Paradox in Non-Cooperative Behavior and Escalation." Journal of Conflict Resolution, 15(1): 109-111.

Skaperdas, Stergios. 2006. "Bargaining Versus Fighting." Defense and Peace Economics, 17(6): 657-676.

Spier, Kathryn E. 1992. "The Dynamics of Pretrial Negotiation.” Review of Economic Studies, 59, 93-108.

Tullock, Gordon. 1980. "Efficient Rent Seeking." In Toward a Theory of the Rent-seeking Society, ed. James M. Buchanan, Robert D. Tollison, and Gordon Tullock. 97-112. College Station, TX: Texas A\&M University Press.

Warnes, Gregory. R., Ben Bolker, and Thomas Lumley. 2008. gtools: various R programming tools. R package version 2.5.0. 
Table 1: Experimental Design and Theoretical Predictions

\begin{tabular}{lcccc}
\hline \hline & & \multicolumn{3}{c}{ Treatment } \\
\cline { 3 - 5 } & Player & Baseline & Binding & Non-Binding \\
\hline Side Payment, $s^{*}$ & 1 & - & 15 & 0 \\
Probability of a Conflict & 2 & 1.00 & 0.00 & 1.00 \\
\cline { 2 - 5 } Equilibrium Expenditure, $e^{*}$ & 1 & 15 & 15 & 15 \\
& 2 & 15 & 15 & 15 \\
\cline { 2 - 5 } Expected Payoff, $E\left(\pi^{*}\right)$ & 1 & 15 & 45 & 15 \\
Available Surplus, $v$ & 2 & 15 & 15 & 15 \\
Equilibrium Surplus, $\Pi^{*}$ & & 60 & 60 & 60 \\
\hline
\end{tabular}

Table 2: Average Individual Per Period Surplus and Expenditure by Treatment

\begin{tabular}{lcccc}
\hline \hline & & \multicolumn{3}{c}{ Treatment } \\
\cline { 2 - 5 } & Player & Baseline & Binding & Non-Binding \\
\hline Side Payment, $s$ & 1 & - & $26.2(4.4)$ & $11.0(12.3)$ \\
Probability of a Conflict & 2 & 1.00 & $0.32(0.47)$ & $0.86(0.35)$ \\
\cline { 2 - 5 } & 1 & $29.3(13.4)$ & $26.0(9.6)$ & $24.1(12.0)$ \\
Average Expenditure, $e$ & 2 & $29.3(13.4)$ & $27.1(8.8)$ & $23.9(12.9)$ \\
\cline { 2 - 5 } & 1 & $0.7(28.9)$ & $22.7(22.0)$ & $4.7(32.7)$ \\
Average Payoff, $\pi$ & 2 & $0.7(28.9)$ & $20.1(20.4)$ & $14.0(30.5)$ \\
Total Surplus, $\Pi$ & & 1.4 & 42.8 & 18.7 \\
\hline
\end{tabular}

Standard deviation in parentheses.

Table 3: Average Gains from Side-Payments by Treatment

\begin{tabular}{lccc}
\hline & \multicolumn{3}{c}{ Treatment } \\
\cline { 2 - 4 } & Baseline & Binding & Non-Binding \\
\hline Total Surplus, $\Pi_{k}$ & 1.4 & 42.8 & 18.7 \\
Surplus Gain, $\Delta \Pi_{k}$ & 0 & 41.4 & 17.3 \\
Probability of Non-Entry, $P_{k}$ & - & 0.68 & 0.14 \\
Surplus Gain From Non-Entry, $v P_{k}$ & - & 40.8 & 8.4 \\
$\%$ Gains From Non-Entry & - & $98.6 \%$ & $48.6 \%$ \\
$\%$ Gains From Reduced Conflict & - & $1.4 \%$ & $51.4 \%$ \\
\hline
\end{tabular}


Table 4: Average Offers and Expenditures in the Non-Binding Treatment

\begin{tabular}{lccc}
\hline Decision & Player & Offer $>0$ & Expenditure \\
\hline \multirow{2}{*}{ Accept } & 1 & $14.9(10.9)$ & $24.9(10.3)$ \\
& 2 & $14.9(10.9)$ & $22.9(12.5)$ \\
\cline { 2 - 4 } Reject & 1 & $9.1(7.8)$ & $26.8(11.5)$ \\
& 2 & $9.1(7.8)$ & $28.6(12.6)$ \\
\hline
\end{tabular}

Standard Deviation in Parentheses.

Table 5: Number of Offers, Rejections and Conflicts

\begin{tabular}{lcc}
\hline \hline & \multicolumn{2}{c}{ Treatment } \\
\cline { 2 - 3 } & Binding & Non-Binding \\
\hline \# of Offers & 540 & 540 \\
\# of Non-Zero Offers & $540(100 \%)$ & $370(68.5 \%)$ \\
\# of Rejections & $175(32.5 \%)$ & $156(28.0 \%)$ \\
\# of Non-Zero Rejections & $175(32.5 \%)$ & $43(11.6 \%)$ \\
\# of Conflicts Avoided & $365(67.5 \%)$ & $78(14.4 \%)$ \\
\hline
\end{tabular}

Table 6: Offers, Accepted Offers and Rejected Offers

\begin{tabular}{lcc}
\hline \hline & \multicolumn{2}{c}{ Treatment } \\
\cline { 2 - 3 } & Binding & Non-Binding \\
\hline Average Offer & $26.2(4.4)$ & $11.0(12.3)$ \\
Average Accepted Offer & $27.7(3.2)$ & $14.3(12.7)$ \\
Average Accepted Offer (With No Entry) & $27.7(3.2)$ & $24.8(13.3)$ \\
Average Rejected Offer & $23.3(5.1)$ & $2.4(5.4)$ \\
\hline
\end{tabular}

Standard deviation in parentheses. 
Figure 1: Histogram of Conflict Expenditures by Treatment with Gaussian Kernel-Density Smoothing

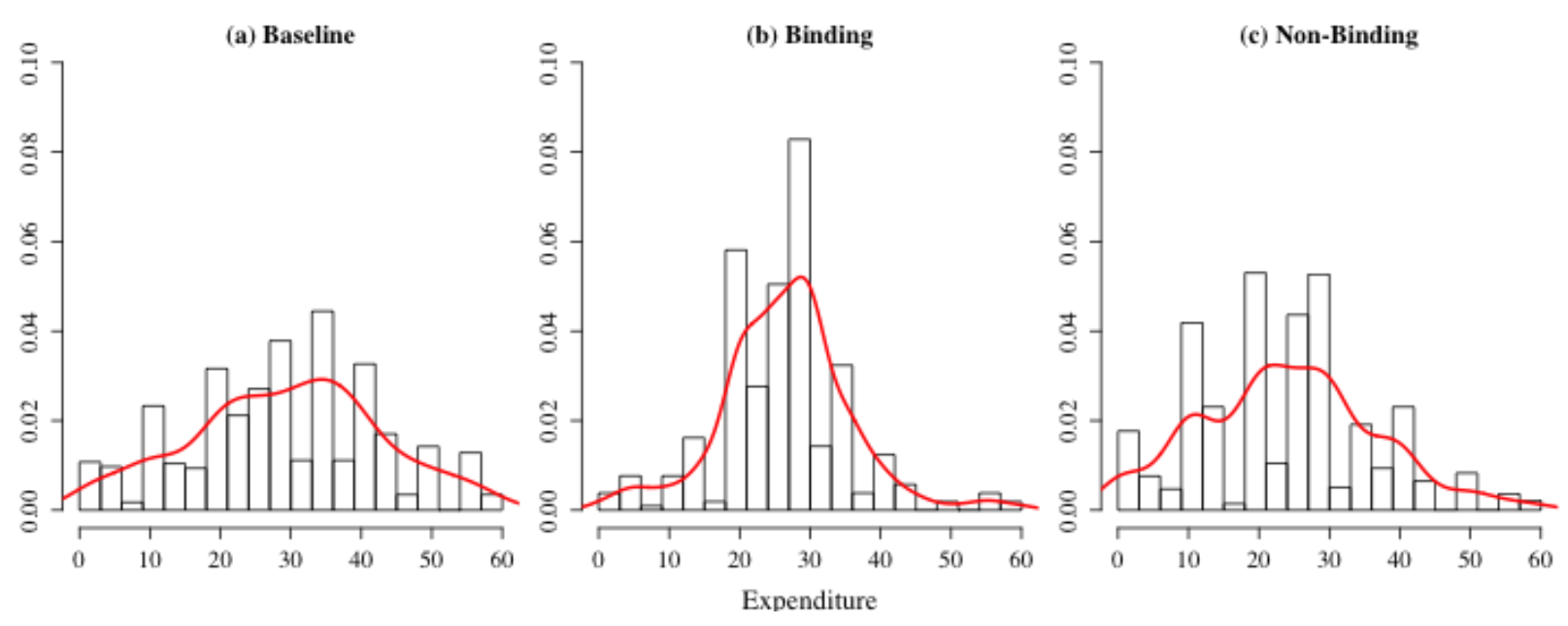

Figure 2: Distribution of Bargaining Stage Offers by Treatment
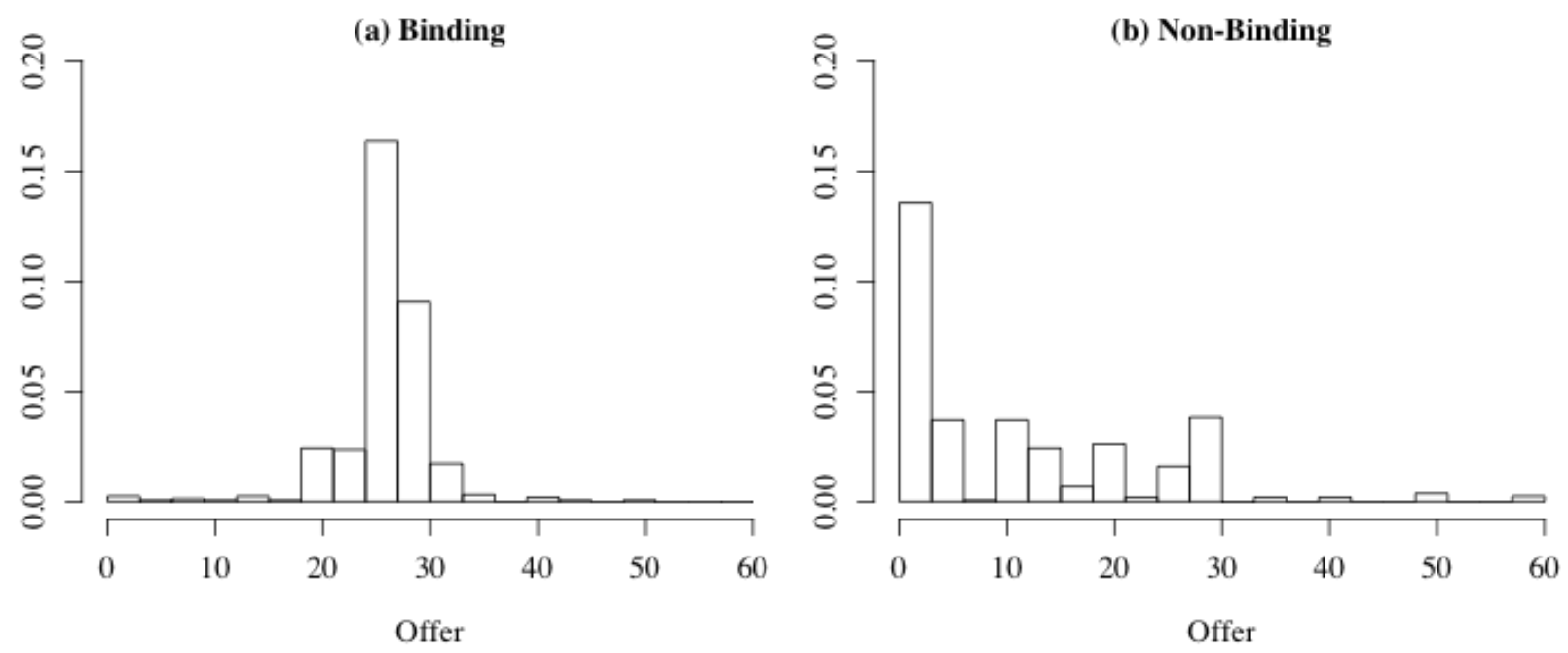


\section{Appendix - Non-Binding Treatment}

\section{GENERAL INSTRUCTIONS}

This is an experiment in the economics of strategic decision-making. Various research agencies have provided funds for this research. The instructions are simple. If you follow them closely and make appropriate decisions, you and the 11 other participants in this experiment can earn an appreciable amount of money, which will be paid to you in CASH at the end of today's experiment.

The currency used in the experiment is francs. Francs will be converted to U.S. Dollars at a rate of 30 francs to $\_1$ dollar. You have already received a $\$ 20.00$ participation fee (this includes the $\$ 7$ show up fee). The experiment will consist of 30 periods and at the end of the experiment we will randomly choose 5 of the 30 periods for actual payment using a bingo cage. We will sum your total earnings for these 5 periods and convert them to a U.S. dollar payment. It is very important that you remain silent and do not look at other people's decisions. If you have any questions, or need assistance of any kind, please raise your hand and an experimenter will come to you. If you talk, laugh, exclaim out loud, etc., you will be asked to leave and you will not be paid. We expect and appreciate your cooperation. The remainder of the instructions will describe the decisions you may face in each period.

\section{INSTRUCTIONS FOR STAGE 1}

At the beginning of each period, you will be randomly and anonymously placed into a group of 2 participants. The composition of your group will be changed randomly every period. Each period will consist of two stages. In stage 1, you and the other participant in your group will bargain for a reward. The reward is worth 60 francs to you and the other participant in your group.

At the beginning of the first period, you will be randomly assigned either the role of Proposer or the role of Responder. You will stay in the same role assignment for the first 15 periods and then change your role assignment for the last 15 periods of the experiment. Each period you will be randomly re-paired with another participant of opposite assignment to form a two-person group. So, if you are Proposer, each period you will be randomly re-paired with another Responder. If you are Responder, each period you will be randomly re-paired with another Proposer.

\section{YOUR DECISION}

In each period, the Proposer will have an opportunity to make an Offer to the Responder. The Proposer may offer any integer number of francs between 0 and 60. An example of the Proposer's decision screen is shown below. 


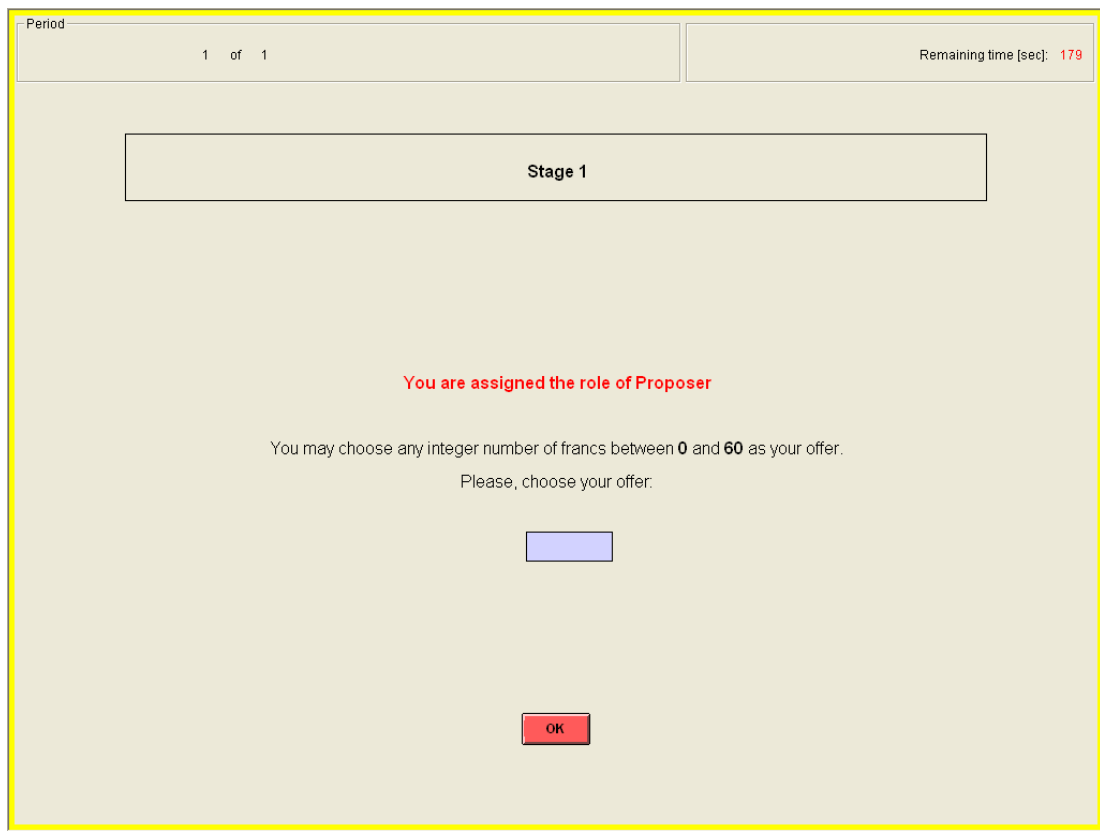

Once the Proposer has entered an offer and submitted that offer to the Responder, the Responder will choose either to Accept or Reject the offer and also whether to enter stage 2 or not. An example of the Responder's decision screen is shown below.

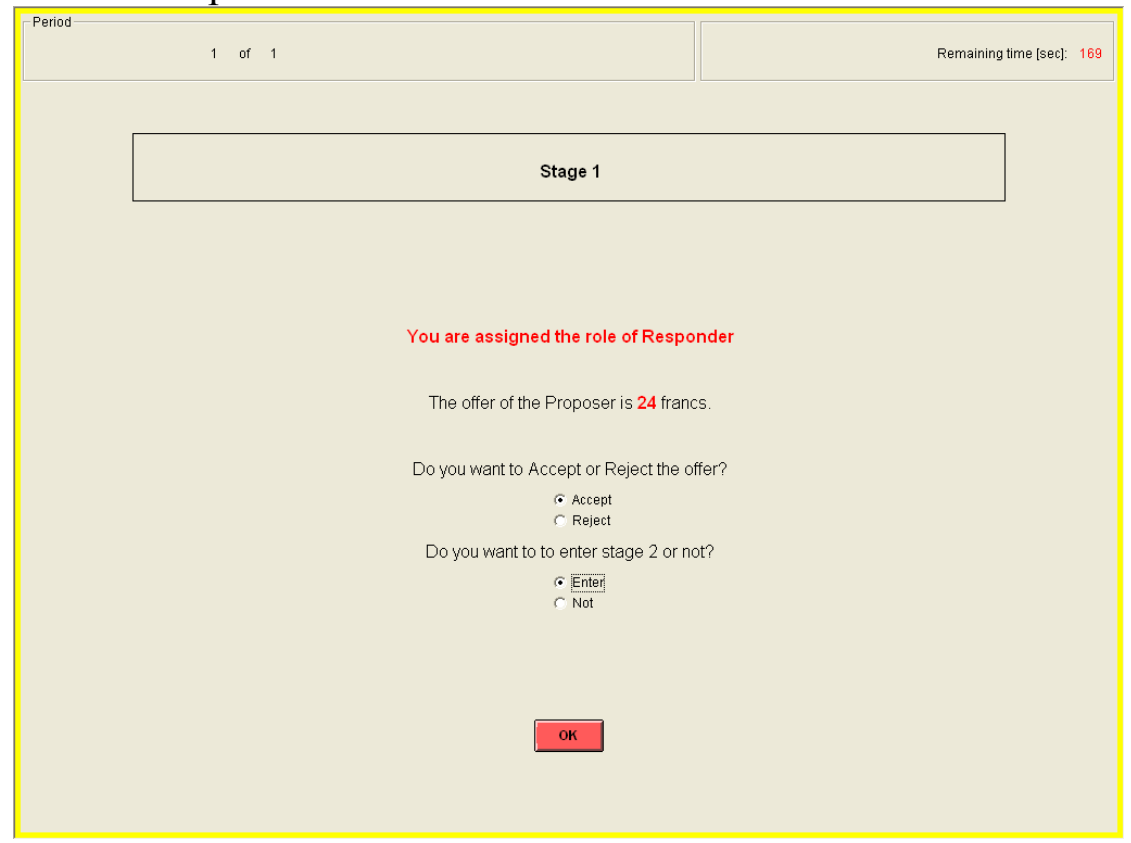

\section{EARNINGS}

If the Responder accepts the offer and decides not to enter stage 2, the Responder receives a payment equal to the offer, and the Proposer receives the 60 franc reward minus the amount of the offer:

Proposer Earnings $\quad=60-$ Offer

Responder Earnings $\quad=$ Offer 
If the Responder rejects the offer and decides not to enter stage 2, the Responder receives a payment equal to 0 , and the Proposer receives the 60 franc reward:

Proposer Earnings $\quad=60$

Responder Earnings $\quad=0$

If the Responder accepts the offer and decides to enter stage 2, the Responder receives a payment equal to the earnings from stage 2 plus the offer, and the Proposer receives the earnings from stage 2 minus the offer:

Proposer Earnings = Earnings in Stage $2-$ Offer

Responder Earnings = Earnings in Stage $2+$ Offer

If the Responder rejects the offer and decides to enter stage 2, the Responder receives a payment equal to the earnings from stage 2, and the Proposer receives the earnings from stage 2:

Proposer Earnings = Earnings in Stage 2

Responder Earnings = Earnings in Stage 2

Note, if the Responder decides not to enter stage 2 (disregarding whether he accepts or rejects the offer) then the period ends after stage 1 . However, if the Responder decides to enter stage 2 (disregarding whether he accepts or rejects the offer) both participants will enter stage 2. In such a case both participants will bid for the 60 franc reward.

\section{INSTRUCTIONS FOR STAGE 2}

\section{DECISION IN STAGE 2}

In stage 2, each participant may bid for the 60 franc reward. You may bid any integer number of francs between 0 and 60. An example of your decision screen is shown below.

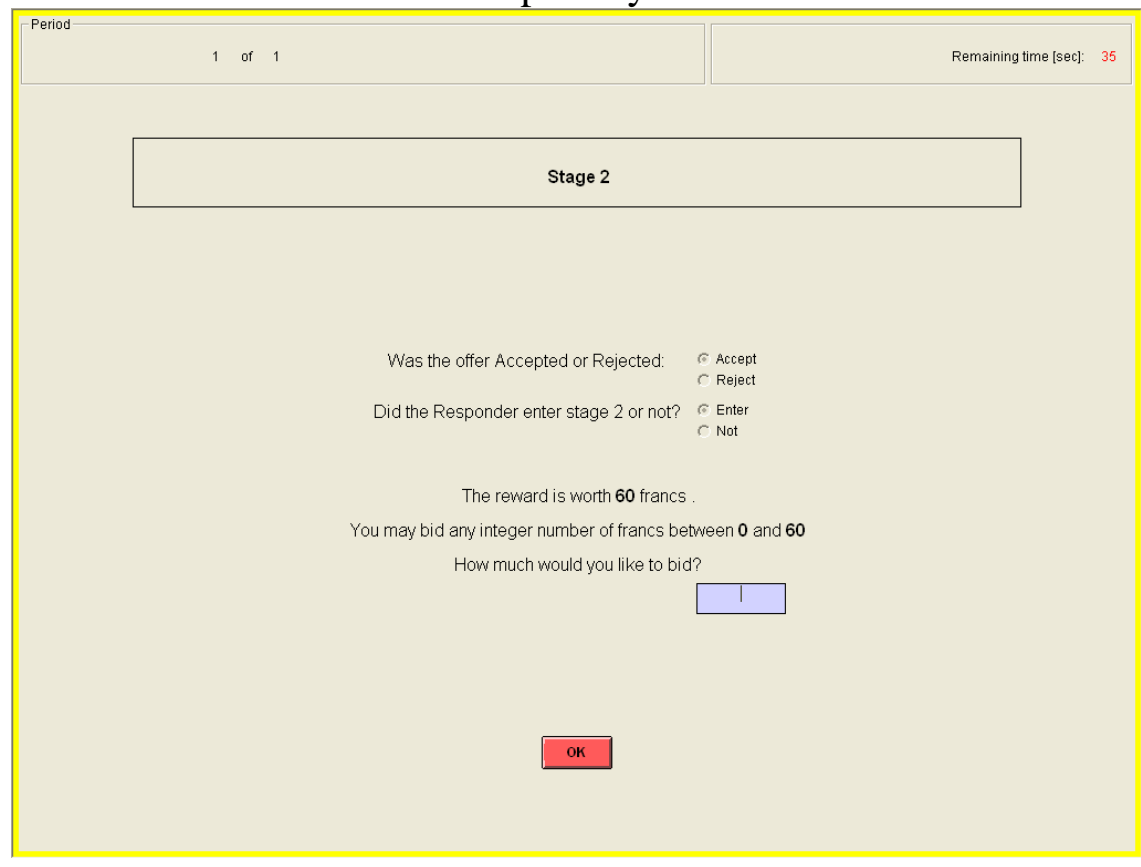

\section{EARNINGS IN STAGE 2}

After all participants have made their decisions, your earnings for the period are calculated. Regardless of who receives the reward, all participants will have to pay their bids. Thus, your earnings in stage 2 will be calculated in the following way:

If you receive the reward: 
Earnings in Stage $2=60-$ Your Bid

If you do not receive the reward:

Earnings in Stage $2=0$ - Your Bid

Remember you have already received a $\$ 20.00$ participation fee (equivalent to 600 francs). Depending on a period, you may receive either positive or negative earnings. At the end of the experiment we will randomly select 5 out of 30 periods for actual payment. You will sum the total earnings for these 5 periods and convert them to a U.S. dollar payment. If the earnings are negative, we will subtract them from your participation fee. If the earnings are positive, we will add them to your participation fee.

What Does my Bid Mean?

The more you bid, the more likely you are to receive the reward. The more the other participant in your group bids, the less likely you are to receive the reward. Specifically, for each franc you bid you will receive one lottery ticket. At the end of each period the computer draws randomly one ticket among all the tickets purchased by you and the other participant in the group. The owner of the drawn ticket receives the reward of 60 francs. Thus, your chance of receiving the reward is given by the number of francs you bid divided by the total number of francs you and the other participant in your group bids.

If both participants bid zero, the reward is randomly assigned to one of the two participants in the group.

\section{Example of the Random Draw}

This is a hypothetical example used to illustrate how the computer is making a random draw. If participant 1 bids 10 francs and participant 2 bids 20 francs, the computer assigns 10 lottery tickets to participant 1 and 20 lottery tickets to participant 2 . Then the computer randomly draws one lottery ticket out of $30(10+20)$. As you can see, participant 2 has higher chance of receiving the reward: $0.67=20 / 30$. Participant 2 has $0.33=10 / 30$ chance of receiving the reward.

After all participants make their bids, the computer will make a random draw which will decide who receives the reward. Then the computer will calculate your period earnings based on your bid and whether you received the reward or not.

At the end of each period, the Proposer's offer, whether the offer was accepted, whether the Responder entered Stage 2, your bid, the other participant's, whether you received the reward or not, and the earnings for the period are reported on the outcome screen as shown below. Once the outcome screen is displayed you should record your results for the period on your Personal Record Sheet under the appropriate heading. An example of the outcome screen is shown below. 


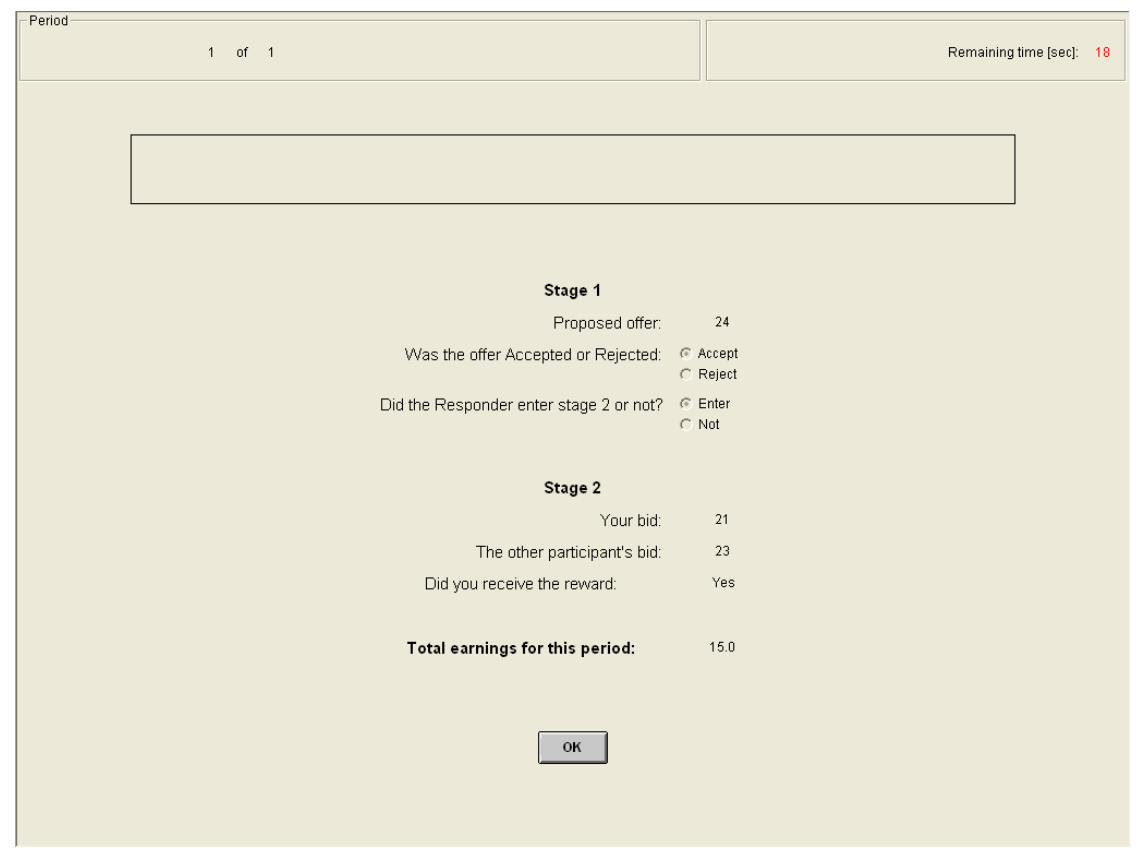

\section{IMPORTANT NOTES}

You will not be told which of the participants in this room are assigned to which group. At the beginning of each period you will be randomly re-grouped with one other participant to form a two-person group. You can never guarantee yourself the reward. However, if you are the Proposer in stage 1, and the Responder decides not to enter stage 2, you will receive the reward. Furthermore, if the experiment proceeds to stage 2 then by increasing your bid in stage 2, you can increase your chance of receiving the reward. In stage 2, regardless of which participant receives the reward, all participants must pay their bids.

Are there any questions? 


\section{Economic Science Institute Working Papers}

2010

10-20 Savikhim, A. and Sheremeta, R. Visibility of Contributions and Cost of Inflation: An Experiment on Public Goods.

10-19 Sheremeta, R. and Shields, T. Do Investors Trust or Simply Gamble?

10-18 Deck, C. and Sheremeta, R. Fight or Flight? Defending Against Sequential Attacks in the Game of Siege.

10-17 Deck, C., Lin, S. and Porter, D. Affecting Policy by Manipulating Prediction Markets: Experimental Evidence.

10-16 Deck, C. and Kimbrough, E. Can Markets Save Lives? An Experimental Investigation of a Market for Organ Donations.

10-15 Deck, C., Lee, J. and Reyes, J. Personality and the Consistency of Risk Taking Behavior: Experimental Evidence.

10-14 Deck, C. and Nikiforakis, N. Perfect and Imperfect Real-Time Monitoring in a Minimum-Effort Game.

10-13 Deck, C. and Gu, J. Price Increasing Competition? Experimental Evidence.

10-12 Kovenock, D., Roberson, B.,and Sheremeta, R. The Attack and Defense of Weakest-Link Networks.

10-11 Wilson, B., Jaworski, T., Schurter, K. and Smyth, A. An Experimental Economic History of Whalers' Rules of Capture.

10-10 DeScioli, P. and Wilson, B. Mine and Thine: The Territorial Foundations of Human Property.

10-09 Cason, T., Masters, W. and Sheremeta, R. Entry into Winner-Take-All and Proportional-Prize Contests: An Experimental Study.

10-08 Savikhin, A. and Sheremeta, R. Simultaneous Decision-Making in Competitive and Cooperative Environments.

10-07 Chowdhury, S. and Sheremeta, R. A generalized Tullock contest.

10-06 Chowdhury, S. and Sheremeta, R. The Equivalence of Contests.

10-05 Shields, T. Do Analysts Tell the Truth? Do Shareholders Listen? An Experimental Study of Analysts' Forecasts and Shareholder Reaction. 
10-04 Lin, S. and Rassenti, S. Are Under- and Over-reaction the Same Matter? A Price Inertia based Account.

10-03 Lin, S. Gradual Information Diffusion and Asset Price Momentum.

10-02 Gjerstad, S. and Smith, V. Household expenditure cycles and economic cycles, 1920 - 2010.

10-01 Dickhaut, J., Lin, S., Porter, D. and Smith, V. Durability, Re-trading and Market Performance.

2009

09-11 Hazlett, T., Porter, D., Smith, V. Radio Spectrum and the Disruptive Clarity OF Ronald Coase.

09-10 Sheremeta, R. Expenditures and Information Disclosure in Two-Stage Political Contests.

09-09 Sheremeta, R. and Zhang, J. Can Groups Solve the Problem of Over-Bidding in Contests?

09-08 Sheremeta, R. and Zhang, J. Multi-Level Trust Game with "Insider" Communication.

09-07 Price, C. and Sheremeta, R. Endowment Effects in Contests.

09-06 Cason, T., Savikhin, A. and Sheremeta, R. Cooperation Spillovers in Coordination Games.

09-05 Sheremeta, R. Contest Design: An Experimental Investigation.

09-04 Sheremeta, R. Experimental Comparison of Multi-Stage and One-Stage Contests.

09-03 Smith, A., Skarbek, D., and Wilson, B. Anarchy, Groups, and Conflict: An Experiment on the Emergence of Protective Associations.

09-02 Jaworski, T. and Wilson, B. Go West Young Man: Self-selection and Endogenous Property Rights.

09-01 Gjerstad, S. Housing Market Price Tier Movements in an Expansion and Collapse.

2008

08-10 Dickhaut, J., Houser, D., Aimone, J., Tila, D. and Johnson, C. High Stakes Behavior with Low Payoffs: Inducing Preferences with Holt-Laury Gambles.

08-09 Stecher, J., Shields, T. and Dickhaut, J. Generating Ambiguity in the Laboratory.

08-08 Stecher, J., Lunawat, R., Pronin, K. and Dickhaut, J. Decision Making and Trade without Probabilities.

08-07 Dickhaut, J., Lungu, O., Smith, V., Xin, B. and Rustichini, A. A Neuronal Mechanism of Choice.

08-06 Anctil, R., Dickhaut, J., Johnson, K., and Kanodia, C. Does Information Transparency

Decrease Coordination Failure? 
08-05 Tila, D. and Porter, D. Group Prediction in Information Markets With and Without Trading Information and Price Manipulation Incentives.

08-04 Caginalp, G., Hao, L., Porter, D. and Smith, V. Asset Market Reactions to News: An Experimental Study.

08-03 Thomas, C. and Wilson, B. Horizontal Product Differentiation in Auctions and Multilateral Negotiations.

08-02 Oprea, R., Wilson, B. and Zillante, A. War of Attrition: Evidence from a Laboratory Experiment on Market Exit.

08-01 Oprea, R., Porter, D., Hibbert, C., Hanson, R. and Tila, D. Can Manipulators Mislead Prediction Market Observers? 